\title{
Reducing Financial and Administrative Corruption Through the Ingredients of the Internal Control System
}

\author{
Murtadha Mohammed Al Hosseini ${ }^{1} \quad$ Layth Ali Al-Tamimi $^{1} \quad$ Ezzaddin Hasan Kadhim $^{2 *}$ \\ 1.Al-Furat Al-Awsat Technical University - Babylon Technical Institute- Department of Accounting \\ 2.Almustaqbal university college/ accounting department.Iraq, Babylon
}

\begin{abstract}
The task of the internal control system in any economic unit is to achieve its objectives by protecting its assets, reliability of its data and adherence to administrative and other policies. The basis of the judgment on the strength or weakness of the internal control system is the basic ingredients of it. It is the clear administrative structure and efficient accounting system. Duties and selection of competent staff and placement in appropriate centers and accurate system to monitor performance as well as the use of all means of automation, all of these should be applied correctly to reduce the cases of financial and administrative corruption .
\end{abstract}

Keywords: Financial corruption, Administrative corruption, Internal Control Ingredients .

DOI: $10.7176 /$ RJFA/10-16-06

Publication date: August $31^{\text {st }} 2019$

\section{Introduction}

The phenomenon of financial and administrative corruption is a serious phenomenon that represents a great danger to the society because of the risk that leads to the erosion of the national economy, and the importance of research in addressing this phenomenon and reduce its harmful effects on society and the national economy through the proper application of the ingredients of the internal control system.( Hlendi, 2009)

The internal audit function is responsible for verifying the implementation of the plans and policies set up to achieve the objectives of the institution, as a result of its direct and supportive association with the senior management. The internal control work is comprehensive from all administrative, financial and technical aspects in order to verify compliance with the regulations and laws within the framework of the National Authority Make the most of your time and money. (Ehsani, 2013 )

In this sense, internal control is a means of detecting deviations, including corruption, which do not comply with the laws and regulations governing the work of the institution on the one hand and affect the factor of confidence. Which has implications for limiting the activity of the creative institution and taking its place among the institutions operating in the same activity. ( Al- Matarana, 2009)

\section{Financial and administrative corruption}

\subsection{The concept of corruption}

Which is the abuse of public power in order to obtain special gains. (Shammari and Al-Fattali, 2011). The researcher believes that corruption is out of the integrity and then out of the laws and regulations and instructions that govern life and society and abuse to the public interest.

Financial corruption is defined as "the misuse of public influence to gain profits and gain or influence at the expense of others or at the expense of laws, regulations and instructions." (Bkou and Ahmad, 2012). It is also known as the "illegal behavior of waste of public money, brokering in projects and arms trade." (Al-Shammari, Al-Fattali, 2011).

The researcher defines financial corruption as a set of financial deviations in violation of financial rules and provisions such as misappropriation of public funds as well as trading through the job and is one of the contemporary economic crimes.

\subsection{The concept of administrative corruption}

Administrative corruption is defined as "moral deviation at the managerial level of senior officials and public servants through bribery, embezzlement, fraud, forgery and the sale of state funds at low prices for personal interests." (Bkua \& Ahmed 2012). corruption refers to all types of deviation, power abuses or illegitimate use of occupational positions (Robins,2013). The researcher defines administrative corruption as an abnormal behavior that occurs when someone tries to achieve his personal interests at the expense of the public interest by exploiting the position in which he is.

\subsection{Types of administrative corruption}

classifies administrative corruption to three categories: (Ehsani, et al., 2013)

1-Black administrative Corruption is an act blamed by masses and political elites, whose doer must be punished. For example, receiving bribe for neglecting safety standards in construction. 
2-Gray administrative Corruption is an act blamed by the majority of elites, but the messes are indifferent about it. For example, delinquency of employees in enforcing laws of lower popularity among people, and only political elites believe in their usefulness.

3-White administrative Corruption is an act apparently against the law, but most members of society (i.e. political elites and the public) do not consider it enough important to be punished. One example is negligence of breaking the regulations, which lost their necessity due to social and cultural changes.

\subsection{The manifestations of financial and administrative corruption}

The various forms of financial and administrative corruption have taken many forms, including: (Khafaji, 2009)

1- Bribery means that a person obtains a benefit that is often financial for the passing or execution of acts other than legislation or the principles of the profession.

2- patronage: the transfer of what the organizations (parties, regions, regions or influential families) of the actions by exploiting their influence without entitlement to them originally.

3- Favoritism: Any preference on the other unjustly, as in the granting of contracts and tenders or lease contracts and investment to specific destinations.

4- Mediation: Any intervention by a person with a functional status or political organization for the benefit of a person who does not deserve the appointment or assignment of the contract or occupation of the office and others.

5- Extortion and Forgery: The person obtains money from other persons, exploiting his or her position through legal or administrative justification or hiding the instructions applicable to the persons concerned, such as in the tax departments, falsifying the school certificate or falsifying the money.

6- looting of public money: This is using the powers granted to the disposal of state funds in violation of instructions or the disposal of goods through the black market or the smuggling of oil wealth through the exploitation of the job site.

7- Corruption that intersects with the laws and regulations: This corruption is related to the laws and regulations relating to the justice system and property rights and banking facilities and credit as well as external financing.

8- Delay in the completion of transactions: This corruption is confined to the process of completing transactions, especially the mission and urgent such as pension and nationality transactions, passports and documents supporting the validity of the issuance of certificates or official books.

\section{The basic ingredients of right internal control systems}

The basic ingredients of internal control are the general set of rules that should be met as a minimum for the establishment of a right and effective control system, and although it is not possible to develop an ideal system of internal control that meets the needs of economic units of all kinds because of the specific circumstances of each unit which may differ from other units, However, there are a set of basic general rules which can be considered as basic ingredients on which any right system of internal control is based, and which can be applied in all economic units that need an effective integrated system of internal control, Weak internal control system and methods, can be summarized as follows:

1-The structure of a clear and efficient administrative organization: The existence of an efficient organizational structure is the basis of the control process in any economic unit, as it is one of the important elements to achieve functional independence between the various departments because of the existence of an important supervisory principle that provides for the strict separation between functional responsibilities to protect against deliberate mistakes And the organizational structure should be flexible enough to allow adjustments required by changes in the policies and objectives of economic unity (Metropolitans, 2009).

In order for the organizational structure to meet the objectives of internal control, there should be a clear mandate for the authorities and the identification and division of duties and responsibilities, especially in large economic units, where each functional level is accountable to another functional level to provide accuracy and efficiency in performance. the researcher agrees with al-Rubaie that the economic unit should establish an organizational structure that defines the departments and divisions within the economic unit to be the basis of the control process, and is characterized by simplicity, clarity, appropriateness, flexibility, and economic (Rubaie, 2014).

2-a right accounting system: a good and effective system of internal control requires the provision of a right accounting system that ensures accountability for the various activities of the economic unit and then prepares its final accounts and controls operations.

Audit Manual No. 4 defines the accounting system as "the set of processes and procedures by which the data and information required to achieve the objectives of the administration are processed, including the maintenance of records and accounting procedures used in the preparation, analysis, calculation, classification, posting, summarization and reporting of information."( Iraqi Accounting and Auditing Standards Board, 2000: 1). 
The availability of an appropriate and integrated accounting system in the economic unit is one of the important factors that help the success and effectiveness of internal control as this accounting system represents the environment in which all financial operations related to the various aspects of activity are accomplished. It is the source of the main information and reports required for different internal and external levels Including internal and external control systems. (Al-Sahan et al., 2006).

3- Detailed procedures for the implementation of duties: The division of duties between the various sections should be taken into account so that one person does not carry out any process from the first to the last, namely, the establishment and retention of the assets resulting from them and accounting for them. The combination of these stages in one hand constitutes a threat to economic unity with the existence of manipulation or embezzlement. . Therefore, the administration must distribute the work in such a way as to guarantee the existence of self-control or automatic control during the implementation of the process, with less opportunities for manipulation, fraud and error (Abdullah, 2010).

The system of internal control to achieve the objectives of the economic unit and to succeed in achieving its goals must include the system of a set of accounting and administrative procedures to ensure that the avoidance of embezzlement and manipulation, and these procedures vary from one economic unit to another depending on the size of the unit and the activity that it exercises

Insurance of assets against all forms of notification, as well as insurance of employees who deal with cash and transferable assets.

1. Implement proper methods for conducting a sudden physical inventory or continuous inventory.

2. follow the policy of forcing employees to take their annual leave at a certain time and assign their work to other employees.

3. The need to follow up on the internal control system because follow-up has a significant impact on the efficiency and effectiveness of the internal control system.

4- Selection of competent staff and placement in appropriate positions: This includes a precise description of the functions of the economic unit and a different program to train staff in the unit to ensure their good choice and the placement of each employee or worker in the right place for him to be able to benefit from different competencies. An efficient employee plays an important role in achieving and achieving the desired economic unity. Therefore, the factor is one of the main components of the effective internal control system.

The effectiveness of the internal control system depends largely on the safety, ability and efficiency of the personnel working within the unit, despite the existence of a good administrative organization, right accounting system, procedures and preventive policies. However, internal control may not succeed in achieving its objectives due to the inefficiency or honesty of the employees of the unit in discharging their responsibilities. (Thomas Winkley, 2010).

The researcher agrees with Al-Rubaie that the selection of competencies commensurate with the burdens of responsibilities and delegated authorities and the involvement of employees in training programs to develop their qualifications and functional competencies and to create a system of incentives that contribute to increasing the efficiency of the performance of employees and lead to the achievement of the objectives efficiently and effectively, and internal auditors to work to enhance their knowledge And their skills through continuous professional development (Rubaie, 2014).

5- Accurate performance monitoring system: Performance evaluation is a form of control, focusing on the analysis of the results reached at different levels of management in order to determine the extent to which the unity of its objectives and how the use of available resources. (Dugji and Khairu, 2012).

The management of the unit is responsible for using its resources efficiently and effectively to achieve its objectives. In this regard, management requires the necessary decisions on how to use the resources and planning to recruit the appropriate staff to work efficiently, as well as the use of cost and other information to make right decisions and achieve the goals of the desired unit. While upgrading the internal control system in the unit from the traditional role to improving the efficiency of its production as well as evaluating the performance of the employees. Performance is monitored directly as the supervision of each person responsible for the work of those who are without it, or indirectly as a tool Such as planning budgets, standard costs, adequacy reports, and internal auditing .

6- Use all automated means: to ensure the accuracy and accuracy of accounting data recorded books and records and preserve the assets of the economic unit of any manipulation or embezzlement.

Automated means used within the accounting system elements within the unit have become important elements in the control and completion of the business as in the counting of cash collected. The use of these means also helps in the accuracy and speed of processing, easy access to information, protection of assets with assistance programs, , And information control . the use of the electronic computer changes the structure of the accounting information system and the procedures followed in the registration process and then the operation of data without human intervention and according to programs prepared in advance as well as reduce the chances of mistakes and fraud in accounting data, but this does not change the objectives of the accounting system. (Rubaie, 2014). 
These are the basic components of the system of internal control right and it differs from the economic unit to another as it can only be available in large economic units that have the potential of material, which has a large number of staff facilitates the division of work in the ideal form. Small economic units can not exist.

After the knowledge of ingredients internal controls as well as financial and administrative corruption and the reasons that led to their occurrence, so will be in the third section to show the role of ingredients internal controls in reducing financial and administrative corruption.

\section{4. methodology of research}

\subsection{Research problem:}

The increasing cases of financial and administrative corruption in all sectors is due to the lack of a clear organizational structure, the absence of a right accounting system, the lack of detailed procedures for carrying out duties, the lack of selection of competent staff, their placement in appropriate positions, the absence of a precise system to monitor performance and the lack of automated means. Search with the following question:

What is the impact ingredients of the internal control system on reducing financial and administrative corruption?

\subsection{The importance of research:}

The importance of the research stems from the necessity of employing the basic ingredients of the internal control systems in the best way to benefit from them in various fields, the most important of which is the field of internal control and its impact on reducing financial and administrative corruption due to the seriousness of corruption on the management of the unit and other parties.

\subsection{Research Objectives:}

The research aims at the following:

1. Identification of corruption (financial and administrative) and manifestations.

2. Identify the ingredients of the internal control system.

3. Clarifying the impact of the ingredients of the internal control system in reducing financial and administrative corruption.

\subsection{The hypothesis of research: The hypothesis of the research is as follows:}

The ingredients of the internal control system (clear and efficient administrative structure, right accounting system, detailed procedures for carrying out duties, selection of competent staff and placement in appropriate positions, accurate performance monitoring system, and the use of all automated means) will reduce financial and administrative corruption

\section{The practical aspect:}

The implementation of the actual data of the Municipality of Babil for 2014, as well as the results prepared by the Federal Audit Office (as a local anti-corruption authority), was adopted in its annual report on the Municipality of Babylon in respect of auditing and auditing activities, accounts and financial statements for the same year.

\subsection{First: Organizational structure:}

The report of the administration lacks some general and specific indicators for the activity of the municipality of Babil during the reporting year, namely, the non-disclosure of information related to the data and accounting policies. The organizational structure was not attached to the data provided to the Federal Financial Control Bureau mentioned measures taken to address the problems and obstacles faced by the Directorate and there is nothing in the administration report shows the activities and expansions in the near future.

In order for the organizational structure to meet the objectives of internal control, there should be a clear mandate for the authorities and the definition and division of duties and responsibilities. Each level of responsibility shall be accountable to another level of work to provide accuracy and efficiency in performance. The organizational structure serves the objectives of internal control over the work of the Municipality of Babil. The possibility of fraud and fraud and reduce financial and administrative corruption and prevent tampering with funds to achieve personal benefits and the detection of errors first and prevent the accumulation of the limits should be clear authority and that each employee knows the duties assigned to the limits of the prevention of leakage between the Department As well as the separation of assets and accounting.

\subsection{Second: The accounting system:}

It turns out that there are errors in the classification of some accounts of the Directorate of Municipalities of Babylon for the year 2014, including:

1 -In Al-Taliah Municipality, the number (293239) was disbursed (810000) ID and recorded in the expenses due 
account 2663 and the correct tabulation is recorded as salaries and wages 3121 because it was paid as a wage for service workers.

2- In the municipality of Al-Qasim, a document of registration no. (574358) was recorded at (400000) dinars and Tab the private sector establishments 2614 and the correct classification is included in the rental of machinery and equipment 3353 because it is due to rental of equipment (renting a two-day excavator.(

3- In Al-Qasim Municipality, the amount of $(29,485,000)$ and the payment of the sum of $(29,485,000)$ were transferred to the municipality of Al-Qasim. The correct salary should be included in salaries and wages 3111 because they were paid for daily workers.

The reason for these errors is the weakness of the unified accounting system for municipalities because it is rigid in the accounting guidance and lacks the methods and procedures used to verify the accuracy and safety of accounting operations and the incorrect use of the book collection because if these operations were recorded first of all these errors occurred and it is clear that the principle was not taken Division of labor, if the division of work and take every person to check the work of the predecessor of these mistakes did not occur.

\subsection{Third: Detailed procedures for carrying out duties :}

It was noted that there is a delay in the submission of financial statements to the Office of Federal Financial Supervision for the year the subject of the report by the Directorate, submitted by the letter No. (4454) on 18/2/2015 Contrary to the book of the Federal Audit Bureau No. (22619) on 9/12/2014 Dated 31/1/2015 for submission and this means not to comply with the deadline specified in the above-mentioned book.

The balance of current accounts frozen after the events of 2003 at the Directorate of the province's treasury is still classified in the account of cash differences for extraordinary circumstances account (1666) instead of the cash account at the banks as it did not appear in the current accounts of the municipalities and the balance of (2040886048) dinars (two billion and forty million and eight hundred And eighty-six thousand and forty-eight dinars).

The total amount allocated for clean-up from Babil province during the year 2014 was (4942147500) (four billion nine hundred and forty-two million five hundred and one hundred and forty-seven thousand five hundred dinars) after deducting the actual expenditure for 2013 of (5491275000) ID (five billion four hundred and ninetyone million two hundred and five) $(10 \%)$ to be the amount allocated for cleaning for the year 2014 according to the Directorate of Municipalities of Babylon and based on the book of the Office of the province of Babylon No. (14670) on 8/6/2014 as being disbursed by the province based on lists submitted by the municipal institutions Note that the amount expended is not shown by the money records In the Directorate. Records should therefore be used to control these amounts and make use of them to clean up cities.

\subsection{Fourth: Selection of Employees:}

The selection of most of the employees has not been done on the jurisdiction and the appropriate place in the municipal institutions, especially in the sections of accounts and auditing. Examples of this in the municipality of Qassim was a middle school employee and works as a senior accountant. In the Nile municipality, In the municipality of Hamzah al-Gharbia, the employee of the preparatory school was an industrial worker and worked in the Audit Division.

The reason for this mistaken choice is not to check the availability of the competency component at the required level in the recruitment of staff, the extent to which the scientific qualifications of the nature of the work of the economic unit, and the failure to set the number of sufficient as often are assigned more than the required number or less, Training for existing staff to ensure that they perform their functions more efficiently and efficiently and provide guidance to new staff.

Therefore, the researcher believes that the selection of competencies commensurate with the burdens of responsibilities and delegated authorities and the involvement of employees in training programs to develop their qualifications and functional competencies and create a system of incentives contributes to increase the efficiency of the performance of employees.

\subsection{Fifth: a precise performance monitoring system:}

The lack of planning of industrial and commercial waste, which led to their appearance within the waste, the inaccuracy in determining the planned and implemented quantities of waste and debris, so should be accurate in the calculation of the quantities actually implemented for waste and rubble and cleaning the streets and be based on a realistic and objective study.

The income due and unpaid for rents due to some tenants of some municipal institutions as of 31/12/2014 amounted to (2093312717) dinars (two billion ninety-three million three hundred and twelve thousand seven hundred and seventeen dinars) of which amounts from previous years and the highest proportion of those debts In my municipality (Western Hamza, the project) contrary to Law No. (56) of 1977 (Amended) collection of government debt. 


\subsection{Sixth: The use of all means:}

The use of automated means in the municipalities of Babylon helps employees to verify the accuracy and accuracy of accounting data recorded in books and records and to preserve the assets of the unit from any manipulation or embezzlement or cases of financial and administrative corruption .The use of automated means and their adaptation to the elements of the accounting system used by the municipalities of Babylon and relying on them within the units are important elements in the control and completion of the business as in the counting of cash collected. The use of these means helps in the accuracy and speed of processing, easy access to information, Help programs, reduce time and cost, and control information.

And that the use of the computer correctly changes the structure of the accounting information system and the procedures followed in the registration process and then the operation of data according to programs prepared in advance as well as reduce the chances of committing mistakes and fraud and reduce cases of financial and administrative corruption because the use of the computer reduces the intervention of staff in the preparation of accounting data However, this does not change the objectives of the accounting system.

The researcher concludes that the elements of the internal control system when applied correctly have a significant role in reducing financial and administrative corruption. This proves the hypothesis of research.

\section{6. conclusion}

The organizational structure is unclear and efficient in the Directorate of Municipalities of Babylon, so there was a breakdown in powers and responsibilities and then increased cases of financial and administrative corruption, There is weakness in the unified accounting system for municipalities because it is stagnant, which caused many errors, including errors in the classification of some accounts, There is a delay in the submission of some financial statements to the Federal Financial Control Bureau by the Directorate of Municipalities of Babylon because of the lack of distribution and division of work correctly, and there are exaggerated figures, which indicates that there are cases of financial and administrative corruption, The selection of most of the staff is wrong, which is not within the jurisdiction in the institutions of the municipality of Babylon, not to put the right person to the right place, There is no good planning in the Directorate of Municipalities of Babylon so did not achieve the required performance, Lack of the use of automated means, such as counting the cash collected and the computer in the departments of the municipalities of Babylon, which increased the chances of committing mistakes and fraud.

\section{References}

1- .Khafaji, Saad Ali Jaber, "The Role of Internal Control System in Reducing Administrative and Financial Corruption", Master Thesis, 2009 p: 41 .

2- Abdullah, Khalid Amin, "the science of auditing," the fifth edition, Dar Wael Publishing, 2010. : 170 .

3- Al- Matarana, Ghassan Falah, "Contemporary Theory Auditing", Second Edition, Dar Al-Masirah Publishing and Distribution, Amman, Jordan, 2009, p: 89 .

4- Al-Dugji, Ali Hussein, and Eman Moayyed Al-Khairo, "Improving the Effectiveness of the Internal Control System in Coso Model", Journal of Economic and Administrative Sciences, Vol 19, No. 70, 2012. P: 407 .

5- Al-Sahan, Abdel-Fattah Mohamed and Saraya, Mohamed El-Sayed and Shehata, Mr., "Modern Internal Auditing and Auditing", University House for Publishing and Distribution, Alexandria, Egypt, 2006 p : 185 .

6- Ehsani, Taboli \& Darooneh. (2013), " Administrative corruption: why and how? " , International Journal of Advanced Studies in Humanities and Social Science, Volume 1, Issue 12 . p :2570 .

7- Financial Audit Bureau, Auditing and Auditing Standards Board of Iraq, Audit Manual No. 4, "Studying and Evaluating the Internal Control System", Baghdad, Iraq, 2000. p: 171 ., : 210 .

8- Hlendi, Alan Ajeeb Mustafa, "The Role of Internal Control in the Electronic Accounting Information System", Legal Accountability Letter, Arab Institute of Certified Public Accountants, Baghdad, 2009. P: 34.

9- $\quad$ Robins, A. (2013). 'Organizational behavior', Prentice Hall. USA. p:436 .

10- Rubaie, Najla Sada Hassoun Mohamed, "The role of internal control in improving the health reality ", a research submitted to the Institute of Higher Accounting and Financial Studies / University of Baghdad,2014. p: 2 .

11- Shammari, Hashim and Ithar Al-Fatly, "Administrative and Financial Corruption and Economic and Social Impact," Dar Al-Yazuri, Amman, Jordan, 2011. P : 17 .

12- Thomas, William, Henke, Emerson, "The Review of Theory and Practice," translated by Ahmad Hamed Hajjaj and Kamal Al-Din Saeed, Dar Al-Marikh Publishing, Riyadh, Saudi Arabia, 2010 p : 379 . 
First Author : He has a master's degree in accounting from the College of Administrative Technology in 2016, Iraq, and has many research published in scientific journals, and has taught accounting courses.

Second Author : Holds a master's degree in accounting information systems from the University of Baghdad in 2015, Iraq. He has published many research papers and has taught many accounting courses.

Third Author: He has a Ph.D. in cost and Management Accounting "CMA" from Baghdad University in 2018, Iraq, and published many researches inside and outside Iraq, and participated in many specialized scientific conferences and was born in 1989 